\title{
Curcumin and its protective and therapeutic uses
}

\author{
Sudhanshu Agrawal ${ }^{1}$, Raj Kumar Goel $^{2}$ \\ ${ }^{1}$ Department of Physiology, Heritage Institute of Medical Sciences, Varanasi, Uttar Pradesh, India. \\ ${ }^{2}$ Department of Pharmacology, Heritage Institute of Medical Sciences, Varanasi, Uttar Pradesh, India. \\ Correspondence to: Sudhanshu Agrawal, E-mail: drsudhanshu.agrawal@gmail.com \\ Received May 30, 2013. Accepted June 8, 2013
}

\section{Abstract}

Curcumin is a yellow orange powder, which is extracted from the turmeric plant (Curcuma longa). Curcumin is the principal curcuminoid of the turmeric (C. longa). Curcumin was first isolated in 1815 and its chemical structure was determined by Roughley and Whiting in 1973. It has been identified as 1,6-heptadiene-3,5-dione-1,7-bis (4-hydroxy-3-methoxyphenyl)-(1e,6e) or diferuloylmethane. Turmeric has been listed as "generally recognized as safe" (GRAS) as a coloring and flavoring agent in food by the US Food and Drug Administration (FDA). As per WHO, as an additive the daily acceptable dose of curcumin for humans has been defined as $0-3 \mathrm{mg} / \mathrm{kg}$ body weight. Curcumin can be administered by different routes as topical, oral, and inhalational. Curcumin inserts deep into the cell membrane in a manner similar to cholesterol. Curcumin has a high lipophilic character, and body fat has a high percentage of bound curcumin. The systemic bioavailability of orally administered curcumin is low in humans and only traces of it have been found in the liver and portal circulation. Piperine has been reported to increase the bioavailability of curcumin. Recently, it has been reported that newly developed nanoparticulate curcumin has better bioavailability. There is a growing list of disease conditions that can be treated by curcumin. Curcumin has been found to have therapeutic effects in wound healing and in various types of arthritis, cardiovascular diseases, diabetes, pulmonary diseases, Parkinson's disease, and in Alzheimer's disease. Curcumin has been reported to have potential role in the treatment of atherosclerosis, arthritis, chronic anterior uveitis, colon cancer, familial adenomatous polyposis, hypercholesteremia, inflammatory bowel disease, pancreatic cancer, pancreatitis, psoriasis, ulcerative colitis, and even HIV.

KEY WORDS: HIV; Colon Cancer; Wound Healing; Nanoparticulate; Lipophilic; Diferuloylmethane; Curcumin; Turmeric

\section{INTRODUCTION}

Extensive research has been done on curcumin over the last century. These studies have revealed its potential as an antiproliferative, anti-invasive, and antiangiogenic agent. The role of curcumin has been suggested as a chemopreventive agent and as a mediator of chemoresistance and radioresistance. Curcumin has been found to have therapeutic effects in wound healing, cardiovascular diseases, diabetes, pulmonary diseases, Parkinson's disease, Alzheimer's disease, and in various types of arthritis. Various other clinical trials suggest that curcumin has potential in the treatment of a number of diseases with poor outcomes such as atherosclerosis, arthritis, chronic anterior uveitis, colon cancer,

\begin{tabular}{|l|l|}
\hline \multicolumn{2}{|c|}{ Access this article online } \\
\hline Website: http://www.njppp.com & Quick Response Code: \\
\hline DOl: 10.5455/njppp.2016.6.3005201596
\end{tabular}

familial adenomatous polyposis, hypercholesteremia, inflammatory bowel disease, pancreatic cancer, pancreatitis, psoriasis, and ulcerative colitis. ${ }^{[1-4]}$

Curcumin is a yellow orange powder and it is extracted from the turmeric plant (Curcuma longa).

\section{TURMERIC}

Curcumin (diferuloylmethane) is the principal curcuminoid of the turmeric, and the other two are demethoxycurcumin and bis-demethoxycurcumin. Turmeric ( $C$. longa) is a plant native to India and Indonesia. Its tuberous rhizomes (root-like structures) have been in use, since ages, as a condiment, spice, food preservative, dye, aromatic stimulant, and as an auspicious material in various Hindu rituals. Turmeric probably originated in India. It has been used in India for at least 2500 years. Turmeric is a well-known therapeutic agent in the Indian and Siddha systems of medicine. Turmeric holds a high place in Ayurvedic medicine as a "cleanser of the body," and it has been described as a treatment for inflammatory diseases. Today, studies find a growing list of disease conditions that can be healed by the active ingredients of turmeric. ${ }^{[5-8]}$

National Journal of Physiology, Pharmacy and Pharmacology Online 2016. (c) 2016 Sudhanshu Agrawal. This is an Open Access article distributed under the terms of the Creative Commons Attribution 4.0 International License (http://creativecommons.org/licenses/by/4.0/), allowing third parties to copy and redistribute the material in any medium or format and to remix, transform, and build upon the material for any purpose, even commercially, provided the original work is properly cited and states its license. 
Turmeric has been known by different names in different cultures, such as kurkum and uqdah-safra in Arabic; yu-chin and yu-jin in Chinese; kunyit and kunir in Indonesian; curcuma and safran-des-indes in French; Indian saffron in English; haldi, haridra, and harita in Sanskrit; and haldi in Hindi. ${ }^{[2,9]}$

Turmeric was assigned the name $C$. longa by Linnaeus. According to taxonomic classification, it belongs to class Liliopsida, subclass Commelinids, order Zingiberales, and family Zingiberaceae. Its genus is Curcuma and its botanical name is C. longa. It is the domestic turmeric, while wild turmeric is known as Curcuma aromatica. ${ }^{[9]}$

\section{Curcumin}

Curcumin was first isolated in 1815 and its chemical structure was determined by Roughley and Whiting in the year 1973. It is obtained from the powdered roots of $C$. longa (turmeric). According to the FPO/WHO Specifications, synonyms of curcumin are turmeric yellow, diferuloylmethane, Kurkum, and C.I. Natural Yellow $3 .^{\left[{ }^{[-12]}\right.}$ It has been identified as 1,6-heptadiene3,5-dione-1,7-bis (4-hydroxy-3-methoxyphenyl)-(1e,6e) or diferuloylmethane. The feruloylmethane structure of curcumin was confirmed and synthesized by Lampe, in 1910. Curcumin is insoluble in water and ether but soluble in ethanol, alkali, ketone, acetic acid and chloroform, acetone, and dimethylsulfoxide. ${ }^{[9,13]}$ The molecular formula of curcumin is $\mathrm{C}_{21} \mathrm{H}_{20} \mathrm{O}_{6}$, its molecular weight is $368.37 \mathrm{~g} / \mathrm{mol}$, and melting point is $183.8^{\circ} \mathrm{C}^{[2,9]}$

Curcumin can exist in at least two tautomeric forms, keto and enol. The enol form is more energetically stable in the solid phase as well as in solution. The enol form can also cross the blood-brain barrier. ${ }^{[3,14]}$

\section{Routes of Administration of Curcumin}

Curcumin has been administered by different routes: topical, oral, and inhalational depending on the use. ${ }^{[15]}$

\section{Safe Dose of Curcumin}

The potential use of curcumin in chemopreventive or therapeutic settings has raised the obvious issues of toxicity and tolerance. Multiple studies have been done so far to establish the safe dose of curcumin. Ringman et al. ${ }^{[16]}$ stated that high doses of curcumin, $400 \mathrm{mg} / \mathrm{kg}$ of body weight, are required to obtain detectable tissue levels in rats. Wahlstrom and Blennow $^{[4]}$ observed that there was no apparent toxic effect of curcumin in rats at doses upto $5 \mathrm{mg} / \mathrm{g}$ of body weight. According to Sharma et al., ${ }^{[17]}$ oral administration of curcumin is safe in humans at doses between 36 and $180 \mathrm{mg} /$ day even if taken upto 4 months. Antony and coworkers ${ }^{[18]}$ stated that curcumin, at a dose of $2000 \mathrm{mg} /$ day, was well tolerated by all the study volunteers without even mild adverse reactions. Different phase-I clinical trials, conducted separately by Shoba et al. $^{[19]}$ and Cheng et al. ${ }^{[20]}$ indicated that curcumin is well tolerated in human subjects when taken at doses as high as $12,000 \mathrm{mg} /$ day ${ }^{[19,20]}$ These results were confirmed by Lao and coworkers. ${ }^{[21]}$ The acceptable daily intake of curcumin as an additive has been defined by the WHO as $0-3 \mathrm{mg} / \mathrm{kg}$ body weight. ${ }^{[12]}$ Turmeric is currently listed as "generally recognized as safe" (GRAS) as a coloring and flavoring agent in food by the US Food and Drug Administration (FDA). ${ }^{[2,16]}$

\section{Membrane Transport, Absorption, and Distribution}

In 1978, Wahlstrom and Blennow conducted an experimental study on five male Sprague-Dawley rats. This study was possibly the first to examine the absorption, distribution, and metabolism of curcumin. Rats were given by gavage a dose of $1 \mathrm{mg} / \mathrm{g}$ of curcumin suspended in arachis (peanut) oil. They observed that after three hours of gavage, curcumin was detected in the plasma of only one of four animals. After $30 \mathrm{~min}$, biliary concentration of curcumin was found to be $1 \mu \mathrm{g} / \mathrm{mL}$ and it remained constant throughout the experiment. About $0.015 \%$ of the administered curcumin was accumulated in the liver, kidneys, and body fat after $3 \mathrm{~h}$. Perfusion of curcumin through the liver resulted in a transitory increase in bile flow. When added to isolated hepatocytes or microsomal suspensions, $90 \%$ of the added curcumin was metabolized within 30 min. $^{[4]}$

Ravindranath and Chandrasekhara observed that after oral administration of $400 \mathrm{mg}$ curcumin to rats, about $60 \%$ of the dose was absorbed. Only traces of curcumin were present in the portal blood, and negligible quantities were observed in the liver and kidney. No curcumin was present in heart blood. Thirty minutes after administration, $90 \%$ of the curcumin appeared in the stomach and small intestine. After $24 \mathrm{~h}$, only $1 \%$ of the curcumin was present there and $38 \%$ was present in the cecum and large intestine. ${ }^{[22]}$

In another study by the same researchers, tritium-labeled curcumin was administered at doses of 400,80 , and $10 \mathrm{mg}$. These studies revealed that curcumin was transformed during absorption. Curcumin was detected in the liver and kidney. At $400 \mathrm{mg}$, significant amounts of labeled curcumin were present in the tissues even 12 days after administration. At all the three doses, 60\%-66\% of curcumin was absorbed. ${ }^{[23]}$ This indicated that increasing the dose of curcumin did not result in higher absorption.

Garcea et al. stated that oral administration of curcumin delivers trace levels of the parent compound and its metabolites into the liver and portal circulation of human subjects. ${ }^{[24]}$ This study was consistent with that by Sharma et al. on 15 patients with colon cancer. In this study, oral doses of 36-180 mg curcumin were administered daily and curcumin levels were measured in blood, urine, and feces upto 29 days. Although curcumin and its metabolites were readily measured in feces, they were absent both in the blood and urine. ${ }^{[17]}$ In the study by Cheng et al., very high doses of curcumin, upto $8000 \mathrm{mg}$, yielded blood levels of only approximately $0.5-2 \mathrm{mM}$ within $1 \mathrm{~h}$ of oral administration. ${ }^{[20]}$ Oral consumption of upto $3600 \mathrm{mg}$ curcumin resulted in curcumin concentrations of $10 \mathrm{nmol} / \mathrm{g}$ tissue in human colorectal mucosa. ${ }^{[24]}$

According to Barry et al., a combination of solid- state Nuclear magnetic Resonance (SSNMR) and differential scanning calorimetry experiments shows curcumin inserts deep into the cell membrane in a manner similar to cholesterol. ${ }^{[25]}$ Thus, 
curcumin has a high lipophilic character. Body fat has a high percentage of bound curcumin. ${ }^{[23]}$

\section{Bioavailability of Curcumin}

The systemic bioavailability of orally administered curcumin is low in humans. The results presented above indicate that oral administration of curcumin furnishes trace levels of the parent compound and its metabolites in the liver and portal circulation. Factors limiting the bioavailability of curcumin include poor absorption, rapid metabolism, and rapid systemic elimination. ${ }^{[1]}$ Piperine has been reported to increase the bioavailability of curcumin. $^{[26]}$ The bioavailability of curcumin ingested in foods may be increased as a result of cooking or dissolution in oil. ${ }^{[27]}$ Mohanty and Sahoo stated that nanoparticulate curcumin is readily dispersed in aqueous medium unlike the free curcumin. They further stated that in mice, the nanoparticulate curcumin was more bioavailable and had a longer half-life than native curcumin. ${ }^{[28]}$ Kanai et al. reported that THERACURMIN, a nanoparticulate curcumin, has improved bioavailability in humans. They also compared various published studies reporting the plasma curcumin levels in human subjects after oral intake of curcumin (Table 1). ${ }^{[2]}$

\section{Protective and Therapeutic Properties of Curcumin}

There is a growing list of disease conditions that can be treated by curcumin. Curcumin ingested orally has been shown to protect multiple tissues against the damage caused by various substances. This has been observed in several studies.

\section{Hepatoprotective Effect of Curcumin}

Singh and Sharma found that curcumin has protective effect against the hepatotoxic effects of organochlorine pesticide lindane. It was observed that pre- and post-treatment with curcumin significantly normalized biochemical as well as histological changes. ${ }^{[35]}$ Park and coworkers observed the protective effect of curcumin in acute or subacute carbon tetrachloride $\left(\mathrm{CCl}_{4}\right)$ induced liver damage in rats. In this study, acute and subacute hepatotoxicity was induced, respectively, by intraperitoneal injection and oral administration of $\mathrm{CCl}_{4}$. Curcumin was found lowering the liver-specific enzymes (serum glutamic pyruvate transaminase [SGPT] and serum glutamic oxaloacetic transaminase [SGOT] in acute liver injury and SGPT and alkaline phosphatase in subacute liver injury) to a significant level. The hydroxyproline content $(100 \mathrm{mg} / \mathrm{kg})$ in the liver of the curcumintreated group was significantly reduced. ${ }^{[36]}$

Pari and Amali stated that tetrahydrocurcumin (an active ingredient of turmeric) and curcumin exert significant protection against chloroquine-induced hepatotoxicity in female Wistar rats. ${ }^{[37]}$ In an animal study, Ebyl and coworkers ${ }^{[38]}$ investigated that pretreatment $(0.05 \mathrm{mg} / \mathrm{g}$ body weight/day for 3 days) with oral curcumin significantly lowered cadmiuminduced lipid peroxidation in liver.

Subba Rao and coworkers ${ }^{[39]}$ observed that the levels of serum and liver cholesterol fell to one-half to one-third in rats fed cholesterol and curcumin in comparison to rats fed cholesterol but no curcumin. Curcumin increased fecal excretion of bile acids and cholesterol, both in normal and hypercholesteremic rats.

Rukkumani and coworkers ${ }^{[40]}$ observed that curcumin and a synthetic analog of curcumin have a protective role against alcohol and thermally oxidized sunflower oil (Poly Unsaturated fatty Acid)-induced oxidative stress in male Wistar rats.

Curcumin and its analogues have protective activity in cultured rat hepatocytes against $\mathrm{CCl}_{4}$, d-galactosamine, peroxide, and ionophore-induced toxicity. ${ }^{[41-43]}$

\section{Protective Effect of Curcumin on Gastrointestinal System The protective effects of curcumin are as follows}

Stomach: Curcumin increases mucin secretion in rabbits and may thus act as a gastroprotectant against irritants. ${ }^{[44]}$ Both antiulcer $^{[45,46]}$ and ulcerogenic ${ }^{[47]}$ effects of curcumin have been reported.

Intestine: Antispasmodic and antiflatulent activities of curcumin have been reported..$^{[9,48]}$ Platel and Srinivasan ${ }^{[49]}$ observed that curcumin enhanced the activity of intestinal lipase, sucrase, and

Table 1: Comparison of the published studies reporting plasma curcumin levels in human subjects after oral intake of curcumin $^{\text {[29] }}$

Subjects Dose of Curcumin (g/day) Sample size Reported plasma Curcumin level

\begin{tabular}{|c|c|c|c|c|}
\hline & & & & an \pm SE) $(\mathrm{ng} / \mathrm{mL})$ \\
\hline Shoba et al. ${ }^{[19]}$ & Healthy volunteers & 2 & 8 & $6 \pm 5$ \\
\hline Cheng et al. ${ }^{[20]}$ & Patients with precancerous lesions & 8 & 2 & $651 \pm 6881$ \\
\hline Sharma et al. ${ }^{[30]}$ & Colorectal cancer patients & 3.6 & 3 & $4 \pm 0.2$ \\
\hline Lao et al. ${ }^{[21]}$ & Healthy volunteers & 12 & $3(1)$ & $57 \mathrm{l}^{\mathrm{a}}$ \\
\hline Garcea et al. ${ }^{[31]}$ & Colorectal cancer patients & 3.6 & 3 & Below 1 \\
\hline Vareed et al. ${ }^{[32]}$ & Healthy volunteers & 8 & 6 & $2300 \pm 260$ \\
\hline Kanai et al. ${ }^{[33]}$ & Pancreatic cancer patients & 8 & 5 & $134 \pm 70$ \\
\hline Sasaki et al. ${ }^{[34]}$ & Healthy volunteers & $0.03^{\mathrm{b}}$ & 7 & $29.5 \pm 13$ \\
\hline Kanai et al. ${ }^{[29]}$ & Healthy volunteers & $0.21^{\mathrm{b}}$ & 6 & $275 \pm 67$ \\
\hline
\end{tabular}

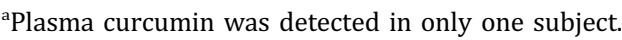

${ }^{\mathrm{b}}$ THERACURMIN was used in these studies. 
maltase. Onder and coworkers ${ }^{[50]}$ observed that curcumin at a dose of $200 \mathrm{mg} / \mathrm{kg}$ ameliorates histopathological damage in the intestine and distant organs against mesenteric ischemia/ reperfusion injury in Wistar albino rats. Almost similar finding was obtained by Okudan and coworkers ${ }^{[51]}$ against intestinal ischemia reperfusion injury induced in rats. Singh and coworkers observed in adult male Swiss albino mice that curcumin protects against the cadmium-induced colonic toxicity and these effects were clearly demarcated by histopathologic findings. ${ }^{[52]}$ Pancreas: Curcumin has been reported to increases the activity of pancreatic lipase, amylase, trypsin, and chymotrypsin. ${ }^{[9]}$

\section{Protective Effect on the Cardiovascular System}

Swamy and coworkers, in albino rats, demonstrated the protective role of curcumin against doxorubicin-induced myocardial toxicity. It was supported by the biochemical and histopathological findings. ${ }^{[53]}$ Curcumin decreases the severity of pathological changes and protects against damage caused by myocardial infarction. ${ }^{[54,55]}$ Curcumin also has significant hypocholesteremic effect in hypercholesteremic rats. ${ }^{[56]}$

\section{Protective and Therapeutic Effect on the Nervous System}

Khuwaja and coworkers ${ }^{[57]}$ concluded that curcumin was helpful in preventing Parkinsonism and has therapeutic potential in combating this devastating neurologic disorder. Curcumin and manganese complex of curcumin offer protective action against vascular dementia by exerting antioxidant activity. ${ }^{[9]}$ Various researchers have found that rural Indian elderly persons (7079 years of age), who eat large amounts of curry, not only have a lower incidence of Alzheimer's disease in comparison to their American counterparts but also have the lowest incidence of Alzheimer's disease in the world..$^{[7,10,11,48,58-64]}$

\section{Effect on lipid metabolism}

Kaur and Meena ${ }^{[65]}$ observed that combinatorial extract of curcumin, piperine, and quercetin could be explored as an alternative therapeutic agent in the treatment of hyperlipidemia in place of conventional antihyperlipidemic drug statins. Shrivastava et al. ${ }^{[6]}$ observed that elevated blood cholesterol, triglycerides, and low-density lipoprotein (LDL) levels were significantly reduced and high-density lipoprotein levels were significantly increased by the administration of curcumin, Gymnema sylvestre, and fenugreek. Curcumin reduces LDL and very low density lipoprotein significantly in plasma and total cholesterol levels in liver along with an increase of $a$-tocopherol level in rat plasma, suggesting in vivo interaction between curcumin and $a$-tocopherol, which may increase the bioavailability of vitamin $\mathrm{E}$ and decrease cholesterol levels. ${ }^{[67]}$

\section{Anti-inflammatory Activity of Curcumin}

Basnet and Skalko-Basnet ${ }^{[68]}$ reviewed that curcumin was a potent anti-inflammatory agent. Curcumin was found to inhibit arachidonic acid metabolism, cyclooxygenase, lipoxygenase, cytokines (interleukins and tumor necrosis factor), nuclear factor- $\kappa \mathrm{B}$, and release of steroidal hormones. Curcumin was reported to stabilize the lysosomal membrane and cause uncoupling of oxidative phosphorylation, besides having strong oxygen radical scavenging activity, which was responsible for its anti-inflammatory property. ${ }^{[7]}$

\section{Antioxidant Activity}

The antioxidant activity of curcumin was reported by Sharma in 1975. ${ }^{[69]}$ Curcumin is a good antioxidant and inhibits lipid peroxidation in rat liver microsomes, erythrocyte membranes, and brain homogenates. ${ }^{[70]}$ It acts as a scavenger of oxygen-free radicals. ${ }^{[71]}$ Unnikrishnan and Rao demonstrated that curcumin and its three derivatives (demethoxy curcumin, bisdemethoxy curcumin, and diacethyl curcumin) protect hemoglobin from oxidation. ${ }^{[72]}$ The effect of curcumin on lipid peroxidation has also been studied in various models by several authors. Lipid peroxidation has a main role in inflammation, in heart diseases, and in cancer. ${ }^{[13]}$ The antioxidant activity of curcumin was studied in refined sunflower oil (RSFO). ${ }^{[73]}$

\section{Antifibrotic Effect}

Punithavathi and coworkers ${ }^{[74]}$ observed that oral administration of curcumin suppressed bleomycin-induced pulmonary fibrosis in rats.

\section{Antiprotozoal Activity}

Antiprotozoal activity of curcumin has been reported by various researchers. Araújo et al. ${ }^{[75]}$ observed that curcumin has excellent activity against promastigote forms of Leishmania amazonensis. Rasmussen et al. ${ }^{[6]}$ reported the efficacy of curcumin against Plasmodium falciparum and L. major.

\section{Antibacterial Activity}

Li et al. ${ }^{[77]}$ observed that in doses of $10.5-43.4 \mu \mathrm{g} / \mathrm{mL}$ curcumin inhibited the growth of Staphylococcus aureus. Singh and Jain ${ }^{[78]}$ observed that out of the three curcuminoids (curcumin, bisdemethoxycurcumin, and demethoxycurcumin) curcumin showed better antibacterial activity against medically important bacteria as Bacillus subtilis, Klebsiella pneumoniae, Escherichia coli, Enterobacter aerogenes, Pseudomonas aeruginosa, S. aureus, and Proteus mirabilis. Various researchers also observed that curcumin has antibacterial activity. Bhavani Shankar and Sreenivasa Murthy ${ }^{[79]}$ observed that both curcumin and the oil fraction of Curcuma suppress growth of several bacteria such as Streptococcus, Staphylococcus, Lactobacillus, and so on. Mahady and coworkers ${ }^{[80]}$ reported that curcumin prevented the growth of Helicobacter pylori in vitro.

\section{Anti-HIV}

Bhullar and coworkers ${ }^{[81]}$ observed that $(E)$-2-(3,4-dimethoxybenzylidene)-6-\{(E)-3-(3,4-dimethoxyphenyl)-acryloyl $\}$ cyclohexanone derivative of curcumin was the strongest human HIV-1 protease inhibitor in vitro. Mazumder et al. ${ }^{[59]}$ demonstrated that curcumin has antiviral activity and suggested that curcumin analogs might be developed as anti-AIDS drugs. Sui 
and coworkers ${ }^{[60]}$ reported that curcumin is a modest inhibitor of HIV-1 and HIV-2 proteases.

\section{Antitumor Activity}

Ha et al. ${ }^{[82]}$ developed water soluble copolymer Cur-PLA-TPGS-, Cur-Gl-, Cur-OCMCS-, and Cur-OCMCS-Fol-encapsulated curcumin nanoparticles and found that these nanoparticles could be used in cancer therapy. Pan et al. ${ }^{[83]}$ evaluated the antitumor effects of the curcumin analogue GL63 on radioresistant nasopharyngeal carcinoma (NPC) CNE2R cells and parental CNE2 cells. According to leading curcumin-cancer researcher Aggarwal, "Curcumin affects virtually every tumor biomarker [of cancer risk] that we have tried. It works through a variety of mechanisms related to cancer development. Cells look at everything in a global way, and inhibiting just one pathway will not be effective." ${ }^{[84]}$ Curcumin acts as a potent anticarcinogenic compound. Among various mechanisms, induction of apoptosis plays an important role in its anticarcinogenic effect. It induces apoptosis and inhibits cell-cycle progression, both of which are instrumental in preventing cancerous cell growth in rat aortic smooth muscle cells. ${ }^{[85]}$ Curcumin exhibits both cancer-preventive activity and growth inhibitory effects on neoplastic cells. ${ }^{[84]}$ Curcumin has been shown to inhibit 7,12-dimethylbenz $[a]$ anthracene-induced and tetradecanoylphorbol-13-acetate-promoted skin tumors, benzo- $(a)$ pyreneinduced forestomach tumors, and azoxymethane-induced intestinal tumors in mice. ${ }^{[86]}$ Kawamori et al. showed that dietary curcumin inhibits colon carcinogenesis when administered during the initiation and post-initiation periods as well as during promotion/progression periods. They suggested that administration of curcumin might retard growth and/or development of existing neoplastic lesions in the colon. They also suggested the potential usefulness of curcumin as a chemopreventive agent for individuals at high risk for colon cancer development, such as patients with polyps. ${ }^{[11]}$ Curcumin has chemopreventive and chemotherapeutic effects on colon cancers. ${ }^{[87]}$ Curcumin suppresses survival, proliferation, invasion, angiogenesis, and metastasis of colon cancer cells. ${ }^{[88]}$

\section{Anticoagulant Activity}

Kim and coworkers ${ }^{[89]}$ suggested that curcumin and its derivative bisdemethoxycurcumin possess antithrombotic activities and daily consumption of the curry spice turmeric might help maintain anticoagulant status. Curcumin showed anticoagulant activity by inhibiting platelet aggregation induced by arachidonate, adrenaline, and collagen, in vitro as well as in vivo, in rat thoracic aorta. ${ }^{[90]}$

\section{Antifertility activity}

Naz observed that incubation of sperm with curcumin caused a concentration-dependent decrease in forward motility of sperm, capacitation/acrosome reaction, and murine fertilization in vitro. It was further observed in the same study that there was a complete block of sperm motility and function within 5-15 min at higher concentrations of curcumin. It was also observed that intravaginal administration of curcumin caused a significant reduction in fertility. These antifertility effects of curcumin were reported to be reversible. ${ }^{[91]}$ Ghosh and coworkers $^{[92]}$ concluded that curcumin may be considered as a potential antifertility agent. Curcumin inhibits $5 a$-reductase, which converts testosterone to $5 a$-dihydrotestosterone, thereby inhibiting the growth of flank organs in hamster. Curcumin also inhibits human sperm motility and has the potential for the development of a novel intravaginal contraceptive. ${ }^{[9]}$

\section{Antidiabetic Effect}

Santoshkumar and coworkers ${ }^{[93]}$ concluded that the ethanolic extract of turmeric has antidiabetic and euglycemic action. Abdel Aziz et al. ${ }^{[94]}$ observed that the water soluble curcumin derivative (NCD), with only $3.0 \%$ curcumin content, has the ability to decrease plasma glucose and increase plasma insulin levels significantly in diabetic rats. Curcumin prevents galactoseinduced cataract onset and maturation at very low doses. ${ }^{\text {[95] }}$ Both turmeric and curcumin decrease blood glucose levels in alloxan-induced diabetes in rats. ${ }^{[96]}$ Pidaran and Leelavinothan ${ }^{[97]}$ observed that curcumin and its metabolite tetrahydrocurcumin decreased blood glucose levels as well as provided significant antihyperlipidemic effect in streptozotocin-induced diabetic rats.

\section{Conclusion}

The available experimental evidences clearly showed that though the acceptable daily intake of curcumin as an additive had been defined by the WHO as $0-3 \mathrm{mg} / \mathrm{kg}$ body weight, it was well tolerated in human subjects in a dose as high as $12,000 \mathrm{mg} /$ day. It was observed that the systemic bioavailability of orally administered curcumin was low in humans. Various researchers tried hard to find out the ways to increase the bioavailability. In one method, piperine has been reported to increase the bioavailability of curcumin. In another one, it was reported that the bioavailability of curcumin in ingested foods may be increased as a result of cooking or dissolution in oil. In another study, it was found that the nanoparticulate curcumin was more bioavailable and had a longer half-life than native curcumin. It was brilliantly studied and instituted that the curcumin was worth as an additive as well as a protective and a therapeutic agent.

\section{REFERENCES}

1. Curcumin from URL: http://en.wikipedia.org/wiki/Curcumin.

2. Goel A, Kumar A, Kunnumakkara B, Aggarwal BB. Curcumin as "Curecumin": from kitchen to clinic. Biochem Pharmacol. 2008;75: 787-809.

3. Kolev TM, Velcheva EA, Stemboliyska BA, Spiteller M. DFT and experimental studies of the structure and vibrational spectra of curcumin Int J Qua Chem. 2005;102:1069-79. doi:10.1002/qua. 20469. 
4. Wahlstrom B, Blennow G. A study on the fate of curcumin in the rat. Acta Pharmacol Toxicol. 1978;43:86-92.

5. Lim GP, Chu T, Yang F, Beech W, Frautschy SA, Cole GM. The curry spice curcumin reduces oxidative damage and amyloid pathology in an Alzheimer transgenic mouse. J Neurosci. 2001;21:8370-7.

6. Mishra S, Palanivelu K. The effect of curcumin (turmeric) on Alzheimer's disease: an overview. Ann Indian Acad Neurol. 2008; 11(1):13-9.

7. Kohli K, Ali J, Ansari MJ, Raheman Z. Curcumin: a natural antiinflammatory agent. Indian J Pharmacol. 2005;37(3):141-7.

8. Akram M, Shahab-Uddin AA, Usmanghani K, Hannan A, Mohiuddin E, Asif M. Curcuma longa and curcumin: a review article. Rom J Biol Plant Biol. 2010;55:65-70.

9. Chattopadhyay I, Biswas K, Bandyopadhyay U, Banerjee RK. Turmeric and curcumin: biological actions and medicinal applications. Curr Sci. 2004;87(1):44-53.

10. Negi PS, Jayaprakasha GK, Jagan Mohan Rao L, Sakariah KK. Antibacterial activity of turmeric oil: a byproduct from curcumin manufacture. J Agric Food Chem. 1999;47:4297-300.

11. Kawamori T, Lubet R, Steele VE. Chemopreventative effect of curcumin, a naturally occurring anti-inflammatory agent, during the promotion/progression stages of colon cancer. Cancer Res. 1999;59:597-601.

12. Summary of Evaluations Performed by the Joint FAO/WHO Expert Committee on Food Additive. Geneva: WHO, 2005Summary of Evaluations Performed by the Joint FAO/WHO Expert Committee on Food Additive. Geneva: WHO, 2005.

13. Araújo CAC, Leon LL. Biological activities of Curcuma longa L Mem Inst Oswaldo Cruz. 2001;96(5):723-8.

14. Balasubramanian K. Molecular orbital basis for yellow curry spice curcumin's prevention of Alzheimer's disease. J Agric Food Chem. 2006;54(10):3512-20.

15. Ahmed S, Anuntiyo J, Malemud CJ, Haqqi TM. Biological basis for the use of botanicals in osteoarthritis and rheumatoid arthritis. eCAM. 2005;2(3):301-8.

16. Ringman JM, Frautschy SA, Cole GM, Masterman DL, Cummings JL. A potential role of the curry spice curcumin in Alzheimer's disease. Curr Alzheimer Res. 2005;2:1-6.

17. Sharma RA, Mc Lelland HR, Hill KA, Ireson CR, Euden SA, Manson $\mathrm{MM}$, et al. Pharmacodynamic and pharmacokinetic study of oral curcuma extract in patients with colorectal cancer. Clin Cancer Res. 2001;7:1894-900.

18. Antony B, Merina B, Iyer VS, Judy N, Lennertz K, Joyal S. A pilot cross-over study to evaluate human oral bioavailability of BCM$95^{\circledR}$ CG (BiocurcumaxTM), a novel bioenhanced preparation of curcumin. Indian J Pharm Sci. 2008;70(4):445-9.

19. Shoba G, Joy D, Joseph T, Majeed M, Rajendran R, Srinivas PS. Influence of piperine on the pharmacokinetics of curcumin in animals and human volunteers. Planta Med. 1998;64(4):353-6.

20. Cheng AL, Hsu CH, Lin JK, Hsu MM, Ho YF, Shen TS, et al. Phase I clinical trial of curcumin, a chemopreventive agent, in patients with high-risk or pre-malignant lesions. Anticancer Res. 2001;21(4B):2895-900.

21. Lao CD, Ruffin MT, Normolle D, Heath DD, Murray SI, Bailey JM, et al. Dose escalation of a curcuminoid formulation. BMC Complement Altern Med. 2006;6:10.

22. Ravindranath V, Chandrasekhara N. Absorption and tissue distribution of curcumin in rats. Toxicology. 1980;16(3):259-65.

23. Ravindranath $\mathrm{V}$, Chandrasekhara N. Metabolism of curcumin: studies with $\left[{ }^{3} \mathrm{H}\right]$ curcumin. Toxicology. 1981-1982;22(4):337-44.

24. Garcea G, Jones DJL, Singh R, Dennison AR, Farmer PB, Sharma RA, et al. Detection of curcumin and its metabolites in hepatic tissue and portal blood of patients following oral administration. Brit J Cancer. 2004;90(5):1011-5.

25. Barry J, Fritz M, Brender JR, Smith PES, Lee DK, Ramamoorthy A. Determining the effects of lipophilic drugs on membrane structure by solid-state NMR spectroscopy: the case of the antioxidant curcumin. J Am Chem Soc. 2009;131(12):4490-8.

26. Anand P, Kunnumakkara AB, Newman RA, Aggarwal BB. Bioavailability of curcumin: problems and promises. Mol Pharmaceutics. 2007;4(6):807-18. doi: 10.1021/mp700113r.

27. Marczylo TH, Verschoyle RD, Cooke DN, Morazzoni P, Steward WP, Gescher AJ. Comparison of systemic availability of curcumin with that of curcumin formulated with phosphatidylcholine. Cancer Chemother Pharmacol. 2007;60(2):171-7. doi:10.1007/s00280006-0355-x.

28. Mohanty C, Sahoo SK. The in vitro stability and in vivo pharmacokinetics of curcumin prepared as an aqueous nanoparticulate formulation. Biomaterials. 2010;31(25):6597-611.

29. Kanai M, Imaizumi A, Otsuka Y, Sasaki H, Hashiguchi M, Tsujiko K, et al. Dose-escalation and pharmacokinetic study of nanoparticle curcumin, a potential anticancer agent with improved bioavailability, in healthy human volunteers Cancer Chemother Pharmacol. 2012;69:65-70. doi: 10.1007/s00280-011-1673-1.

30. Sharma RA, Euden SA, Platton SL, Cooke DN, Shafayat A, Hewitt HR, et al. Phase I clinical trial of oral curcumin: biomarkers of systemic activity and compliance. Clin Cancer Res. 2004;10(20):6847-54.

31. Garcea G, Berry DP, Jones DJ, Singh R, Dennison AR, Farmer PB, et al. Consumption of the putative chemopreventive agent curcumin by cancer patients: assessment of curcumin levels in the colorectum and their pharmacodynamic consequences. Cancer Epidemiol Biomarkers Prev. 2005;14:120-5.

32. Vareed SK, Kakarala M, Ruffin MT, Crowell JA, Normolle DP, Djuric $\mathrm{Z}$, et al. Pharmacokinetics of curcumin conjugate metabolites in healthy human subjects. Cancer Epidemiol Biomarkers Prev. 2008;17(6):1411-7.

33. Kanai M, Yoshimura K, Asada M, Imaizumi A, Suzuki C, Matsumoto $\mathrm{S}$, et al. A phase I/II study of gemcitabine-based chemotherapy plus curcumin for patients with gemcitabine-resistant pancreatic cancer Cancer Chemother Pharmacol. 2011;68(1):157-64. doi: 10.1007/ s00280-010-1470-2.

34. Sasaki H, Sunagawa Y, Takahashi K, Imaizumi A, Fukuda H, Hashimoto $\mathrm{T}$, et al. Innovative preparation of curcumin for improved oral bioavailability. Biol Pharm Bull. 2011;34(5):660-5.

35. Singh R, Sharma P. Hepatoprotective effect of curcumin on lindaneinduced oxidative stress in male wistar rats. Toxicol Int. 2011;18 (2):124-9.

36. Park E-J, Jeon CH, Ko G, Kim J, Sohn DH. Protective effect of curcumin in rat liver injury induced by carbon tetrachloride. J Pharm Pharmacol. 2000;52(4):437-40.

37. Pari L, Amali DR. Protective role of tetrahydrocurcumin (THC) an active principle of turmeric on chloroquine induced hepatotoxicity in rats. J Pharm Pharmaceut Sci. 2005;8(1):115-23.

38. Eybl V, Kotyzová D, Bludovská M. The effect of curcumin on cadmium-induced oxidative damage and trace elements level in the liver of rats and mice. Toxicol Lett. 2004;151:79-85.

39. Subba Rao D, Chandra Sekhara N, Satyanarayana MN, Srinivasan M. Effects of curcumin on serum and liver cholesterol levels in the rat. J. Nutrition. 1970;100:1307-16.

40. Rukkumani R, Aruna K, Varma PS, Rajasekaran KN, Menon VP. Comparative effects of curcumin and an analog of curcumin on alcohol and PUFA induced oxidative stress J Pharm Pharmaceut Sci. 2004;7(2):274-83. 
41. Hikino H. Antihepatotoxic activity of crude drugs. Yakugaku zasshi. 1985;105:109-18.

42. Song EK, Cho H, Kim JS, Kim NY, An NH, Kim JA, et al. Diarylheptanoids with free radical scavenging and hepatoprotective activity in vitro from Curcuma longa. Planta Med. 2001;67:876-7.

43. Chey WY, Millikan L, Lee KY, Watanabe S, Shiratori K, Takeuchi T. Effect of 1-phenylpentanol on release of secretin and exocrine pancreatic secretion in dogs and humans. Gastroenterology. 1983; 84:1578-84

44. Lee CJ, Lee JH, Seok JH, Hur GM, Park YC, Seol IC, et al. Effects of baicalein, berberine, curcumin and hespiridin on mucin release from airway goblet cells. Planta Med. 2003;69:523-6.

45. Dasgupta SR, Sinha M, Sahana CC, Mukherjee BP. A study of the effect of an extract of Curcuma longa Linn. on experimental gastric ulcers in animals. Indian J Pharmacol. 1969;1:49-54.

46. Sinha M, Mukherjee BP, Mukherjee B, Dasgupta SR. Study on the 5-hydroxytryptamine contents in guinea pig stomach with relation to phenylbutazone induced gastric ulcers and the effects of curcumin thereon. Indian J Pharmacol. 1974;6:87-96.

47. Gupta B, Kulshrestha VK, Srivastava RK, Prasad DN. Mechanisms of curcumin induced gastric ulcer in rats. Indian J Med Res. 1980;71: 806-14.

48. Itthipanichpong C, Ruangrungsi N, Kemsri W, Sawasdipanich A. Antispasmodic effects of curcuminoids on isolated guinea-pig ileum and rat uterus. J Med Assoc Thai. 2003;86:299-309.

49. Platel K, Srinivasan K. Digestive stimulant action of spices: a myth or reality? Indian J Med Res. 2004;119(5):167-79.

50. Onder A, Kapan M, Gümüş $M$, Yüksel H, Böyük A, Alp H, et al. The protective effects of curcumin on intestine and remote organs against mesenteric ischemia/reperfusion injury Turk J Gastroenterol. 2012;23(2):141-7. doi: 10.4318/tjg.2012.0446.

51. Okudan N, Belviranlı M, Gökbel H, Oz M, Kumak A. Protective effect of curcumin supplementation on intestinal ischemia reperfusion injury Phytomedicine. 2013;20(10):844-8. doi: pii:S0944-7113(13) 00131-1.10.1016/j.phymed.2013.03.022.

52. Singh P, Mogra P, Sankhla V, Deora K. Protective effects of curcumin on cadmium chloride induced colon toxicity in Swiss albino mice. J Cell Mol Biol. 2011;9(1):31-6.

53. Swamy AV, Gulliaya S, Thippeswamy A, Koti BC, Manjula DV. Cardioprotective effect of curcumin against doxorubicin-induced myocardial toxicity in albino rats. Indian J Pharmacol. 2012;44(1): 73-7. doi: 10.4103/0253-7613.91871.

54. Nirmala C, Puvanakrishnan R. Protective role of curcumin against isoproterenol induced myocardial infarction in rats. Mol Cell Biochem. 1996;159(2):85-93.

55. Kim YS, Park HJ, Joo SY, Hong MH, Kim KH, Hong YJ, et al. The protective effect of curcumin on myocardial ischemia-reperfusion injury. Korean Circ J. 2008;38:353-59.

56. Patil TN, Srinivasan M. Hypocholesteremic effect of curcumin in induced-hypercholesteremic rats. Indian J Exp Biol. 1971;9: 167-9.

57. Khuwaja G, Khan MM, Ishrat T, Ahmad A, Raza SS, Ashfaq M, et al. Neuroprotective effects of curcumin on 6-hydroxydopamine-induced Parkinsonism in rats: Behavioral, neurochemical and immunohistochemical studies Brain Res. 2011;1368:254-63. doi:10.1016/j.brainres.2010.10.023.

58. Bourne KZ, Bourne N, Reising SF, Stanberry LR. Plant products as topical microbicide candidates: assessment of in vitro and in vivo activity against herpes simplex virus type 2. Antiviral Res. 1999; 42:219-26.
59. Mazumder A, Wang S, Neamati N, Nicklaus M, Sunder S, Chen J, et al. Antiretroviral agents as inhibitors of both human immunodeficiency virus type 1 integrase and protease. J Med Chem. 1996;39:2472-81.

60. Sui Z, Salto R, Li J, Craik C, Ortiz de Montellano PR. Inhibition of the HIV-1 and HIV-2 proteases by curcumin and curcumin boron complexes. Bioorg Med Chem. 1993;1:415-22.

61. James JS. (ATN) Curcumin update: could food spice be low-cost antiviral? AIDS Treat News. 1993;176:1-3.

62. Turmeric Is "The Spice of Life". by Will Block from URLwww.lifeenhancement.com/article_template.asp?ID=995 Turmeric Is "The Spice of Life". by Will Block from URLwww.life-enhancement.com/ article_template.asp?ID=995.

63. Douichene S, Djebli N, Ahmed M, Zerrouki K. Neuroprotective effect of curcumin with a fixator of absorption against both aluminium neurotoxicity and alzheimer's disease (Experimental studies in mice) J Alzheimers Dis Parkinsonism. 2012;2:107 doi:10.4172/ 2161-0460.1000107.

64. Choudhary N, Sekhon BS. Potential therapeutic effect of curcumin: an update. J Pharm Educ Res. 2012;3(2):64-71.

65. Kaur G, Meena C. Evaluation of anti-hyperlipidemic potential of combinatorial extract of curcumin, piperine and quercetin in triton-induced hyperlipidemia in rats Sci Int. 2013;1:57-63. doi: 10.5567/sciintl.2013.57.63.

66. Shrivastava R, Solanki SS, Tomar V, Garud N, Garud A, Kannojia P, et al. Research article comparative evaluation of polyherbal combination for hypolipidemic activity. IJPSDR. 2009;1(1):9-12.

67. Kamal-Eldin A, Frank J, Razdan A, Tengblad S, Basu S, Vessby B. Effects of dietary phenolic compounds on tocopherol, cholesterol, and fatty acids in rats. Lipids. 2000;35:427-35.

68. Basnet P, Skalko-Basnet N. Curcumin: an anti-inflammatory molecule from a curry spice on the path to cancer treatment Molecules. 2011;16:4567-98. doi:10.3390/molecules16064567.

69. Sharma OP. Antioxidant activity of curcumin and related compounds. Biochem Pharmacol. 1976;25:1811-2.

70. Reddy AC, Lokesh BR. Effect of dietary turmeric (Curcuma longa) on iron-induced lipid peroxidation in the rat liver. Food Chem Toxicol. 1994;32:279-83.

71. Subramanian M, Sreejayan Rao MNA, Devasagayam TPA, Singh BB. Diminution of singlet oxygen induced DNA damage by curcumin and related antioxidants. Mutat Res. 1994;311:249-55.

72. Unnikrishnan MK, Rao MNA. Curcumin inhibits nitrogen dioxide induced oxidation of hemoglobin. Mol Cell Biochem. 1995;146 (1):35-7.

73. Rege S, Momin S, Wadekar S, Pratap A, Bhowmick D. Effect of demethoxycurcumin and bisdemethoxycurcumin on antioxidant activity of curcumin in refined sunflower oil J Food Process Preserv. 2014;38:296-303. doi: 10.1111/j.1745-4549.2012.00777.x.

74. Punithavathi D, Venkatesan N, Babu M. Curcumin inhibition of bleomycin induced pulmonary fibrosis in rats. Br J Pharmacol. 2000;131:169-72.

75. Araújo CAC, Alegrio LV, Castro D, Lima MEF, Leon LL. Leishmania amazonensis: in vivo experiments with diarylheptanoids from Leguminosae and Zingiberaceae plants Mem Inst Oswaldo Cruz. 1998;93(Suppl II):306.

76. Rasmussen HB, Christensen SB, Kvist LP, Karazmi A. A simple and efficient separation of the curcumins, the antiprotozoal constituents of Curcuma longa. Planta Med. 2000;66:396-8.

77. Li X, Jin C, He J, Zhou J, Wang H, Dai B, et al. Microcalorimetric investigation of the antibacterial activity of curcumin on Staphylococcus 
aureus coupled with multivariate analysis. J Ther Ana Calor. 2012;109 (1):395-402. doi: 10.1007/s10973-011-1428-6.

78. Singh RP, Jain DA. Evaluation of antimicrobial activity of curcuminoids isolated from turmeric. IJPLS. 2012;3(1):1368-76.

79. Bhavani Shankar TN, Sreenivasa Murthy V. Effect of turmeric (Curcuma longa) fractions on the growth of some intestinal and pathogenic bacteria in vitro Indian J Exp Biol. 1979;17: 1363-6.

80. Mahady GB, Pendland SL, Yun G, Lu ZZ. Turmeric (Curcuma longa) and curcumin inhibit the growth of Helicobacter pylori, of group carcinogen. Anticancer Res. 2002;22:4179-81.

81. Bhullar KS, Jha A, Youssef D, Rupasinghe HPV. Curcumin and its carbocyclic analogs: structure-activity in relation to antioxidant and selected biological properties Molecules. 2013;18:5389-404. doi:10.3390/molecules18055389.

82. Ha PT, Le MH, Hoang TMN, Le TTH, Duong TQ, Tran THH, et al Preparation and anti-cancer activity of polymer-encapsulated curcumin nanoparticles Adv Nat Sci: Nanosci Nanotechnol. 2012;3(3) 035002 doi: 10.1088/2043-6262/3/3/035002 http://iopscience. iop.org/2043-6262/3/3/035002.

83. Pan $Y$, Xiao J, Liang G, Wang $M$, Wang D, Wang $S$, et al. A new curcumin analogue exhibits enhanced antitumor activity in nasopharyngeal carcinoma Oncol Rep. 2013;30(1):239-45. doi: 10.3892/or.2013.2457. Epub 2013 May 14

84. Craig Weatherby. Curry spices versus colorectal cancer Vital Choices. 2006;96(3). from URL: http://newsletter.vitalchoice.com/ e_article000671218.cfm?x=b6TLBFC,b1kJpvRw,w.

85. Chen HW, Huang HC. Effect of curcumin on cell cycle progression and apoptosis in vascular smooth cells. Br J Pharmacol. 1998; 124:1029-40.

86. Chuang SE, Kuo ML, Hsu CH, Chen CR, Lin JK, Lai GM, et al Curcumin-containing diet inhibits diethylnitrosamine-induced murine hepatocarcinogenesis. Carcinogenesis. 2000;21(2): 331-5.

87. Wang X, Wang Q, Ives KL, Evers BM. Curcumin inhibits neurotensinmediated interleukin-8 production and migration of hct116 human colon cancer cells. Clin Cancer Res. 2006;12:5346-55.
88. Ajaikumar B, Kunnumakkara AB, Guha S, Aggarwal BB. Curcumin and colorectal cancer: add spice to your life Curr Colorectal Cancer Rep. 2009;5(1):5-14.

89. Kim DC, Ku SK, Bae JS. Anticoagulant activities of curcumin and its derivative. BMB Rep. 2012;45(4):221-6.

90. Srivastava KC, Bordiab A, Verma SK. Curcumin, a major component of food spice turmeric (Curcuma longa) inhibits aggregation and alters eicosanoid metabolism in human blood platelets. PLEFA. 1995;52(4):223-7.

91. Naz RK. Can curcumin provide an ideal contraceptive? Mol Reprod Dev. 2011;78(2):116-23. doi: 10.1002/mrd.21276.

92. Ghosh AK, Das AK, Patra KK. Studies on antifertility effect of rhizome of Curcuma longa linn. AJPLS. 2011;1(4):349-53.

93. Santoshkumar J, Manjunath S, Mariguddi DD, Kalashetty PG, Dass P, Manjunath C. Anti-diabetic effects of turmeric in alloxan induced diabetic rats. JEMDS. 2013;2(11):1669-79.

94. Aziz MTA, El-Asmar MF, El-Ibrashy IN, Rezq AM, Al-Malki Al, Wassef MA, et al. Effect of novel water soluble curcumin derivative on experimental type- 1 diabetes mellitus (short term study). Diabetol Metab Syndr. 2012;4:30 http://www.dmsjournal.com/ content/4/1/30.

95. Suryanarayana P, Krishnaswamy K, Reddy GB. Effect of curcumin on galactose-induced cataractogenesis in rats. Mol Vis. 2003; 9:223-30.

96. Arun N, Nalini N. Efficacy of turmeric on blood sugar and polyol pathway in diabetic albino rats. Plant Foods Hum Nutr. 2002;57:41-52.

97. Pidaran M, Leelavinothan P. Protective role of tetrahydrocurcumin on changes in the fatty acid composition in streptozotocinnicotinamide induced type 2 diabetic rats. J Appl Biomed. 2007;5:31-8.

How to cite this article: Agrawal S, Goel RK. Curcumin and its protective and therapeutic uses. Natl J Physiol Pharm Pharmacol 2016;6:1-8.

Source of Support: Nil, Conflict of Interest: None declared. 